\title{
An intelligent Model for Defect Prediction in Spot Welding
}

\author{
Christopher Paulraj a , Dr. V. Joseph Raj ${ }^{\text {b }}$

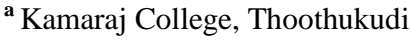 \\ Email:åChristopher.paulraj@gmail.com, ${ }^{\mathrm{b}}$ v.jose08@gmail.com
}

Article History: Received: 10 November 2020; Revised 12 January 2021 Accepted: 27 January 2021; Published online: 5 April 2021

\begin{abstract}
There are more than 30\% defect in the spot welding of cars and randomly chosen cars are performed ultrasound or destructive testing. This makes the process very vulnerable and unpredictable. This results in huge reworks, productivity, monetary loss and negative impact on brand name.

This research paper presents the prediction of defect using machine learning models and as well forecasting models in spot welding through optimized methodology. This defect prediction model is useful in determining the defects that are likely to occur during spot welding. The forecasting model for process parameters data pattern, trends, etc. helps to identify the link between predicted defects. This model can evolve and improve over time by considering data from previous phases and history data of the spot welding cycle. Predicting the defects before testing begins improves the quality of the product being delivered and helps in planning and decision making for future spot welding.

The optimized defect prediction methodology in spot welding reduces the defects and predicted sample for testing which reduces the rework and increase the productivity, monetary value and brand name.

The experimental result shows that the spot-welding methodology has shown improvement over existing spot-welding method. Please see the six-sigma (Fig:13) chart for before and after improvement curve and value.
\end{abstract}

Keywords: Defects, Machine Learning Algorithms, Process Parameters, Time Series Algorithms and Visualization.

\subsection{Objective}

The proposal is to create the methodology using Probabilistic Model and Machine Learning Algorithms to predict the defects in the spot weld and the defect prediction accuracy, sensitivity and specificity is more than $80 \%$. The predicted defects used for

* Reducing the defects by changing or setting contributors.

* Taking samples for testing based on prediction rather than random.

* The process parameter's abnormal behavior are notified to stop production.

\subsection{Problem Domain}

The current process of the spot-welding defects are identified through ultrasound probe measurement and destructive testing. The cost for both the testing are very high so very few randomly selected spot welds are used for testing. Below are the problems which exist in the process:

* Defects in the Production

* The defects are unnoticed because very few randomly selected spot weld tested.

* The defects are raised after a process parameter goes out of bounds. There is no method currently available to see if a particular parameter goes out of control.

\section{Introduction}

Spot welding is most widely used process in manufacturing of car. The effectiveness, efficiency, look and feel and other factors of the car depends on the quality of spot welding.

Spot welding is one form of resistance welding, which is a method of welding two or more metal sheets together without using any filler material by applying pressure and current to the area to be welded. The process is used for joining sheet materials and uses shaped copper alloy electrodes to apply pressure and convey the electrical current through the work pieces. In all forms of resistance welding, the parts are locally heated. The material between the electrodes yields and is squeezed together. It then melts, destroying the interface between the parts. The current is switched off and the "nugget" of molten materials solidifies forming the joint. 


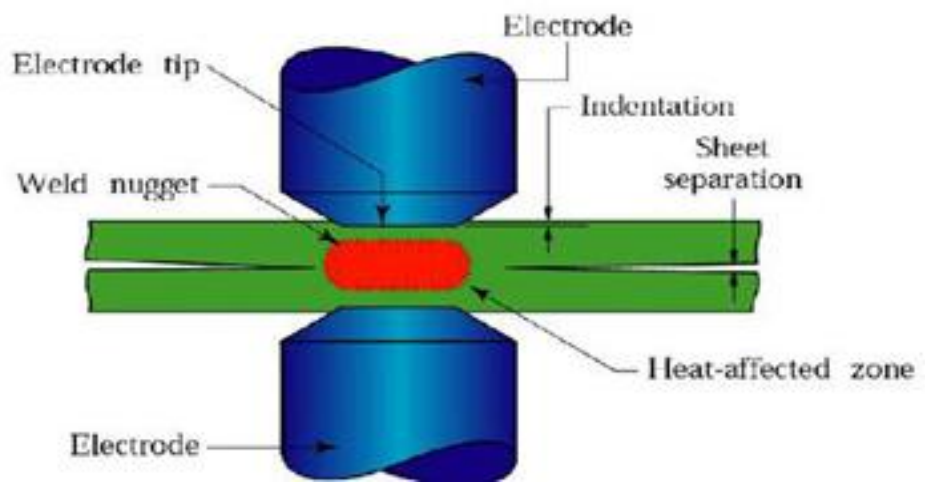

Source: www2.warwick.ac.uk

Figure 1: Cross Section of Spot Welding

Spot welding finds its major application in the form of 'Body-In-White' (BIW) manufacturing. BIW is the vehicle shell that forms the base structure on which other parts of the car line body panels, doors, hood, powertrain, axles, trims etc. are assembled. BIW is manufactured from sheet metal wherein different sheet metal components are joined (usually by welding) to form the total BIW assembly.

Source: www.areus-project.eu

Figure 2: A robotic BIW weld line
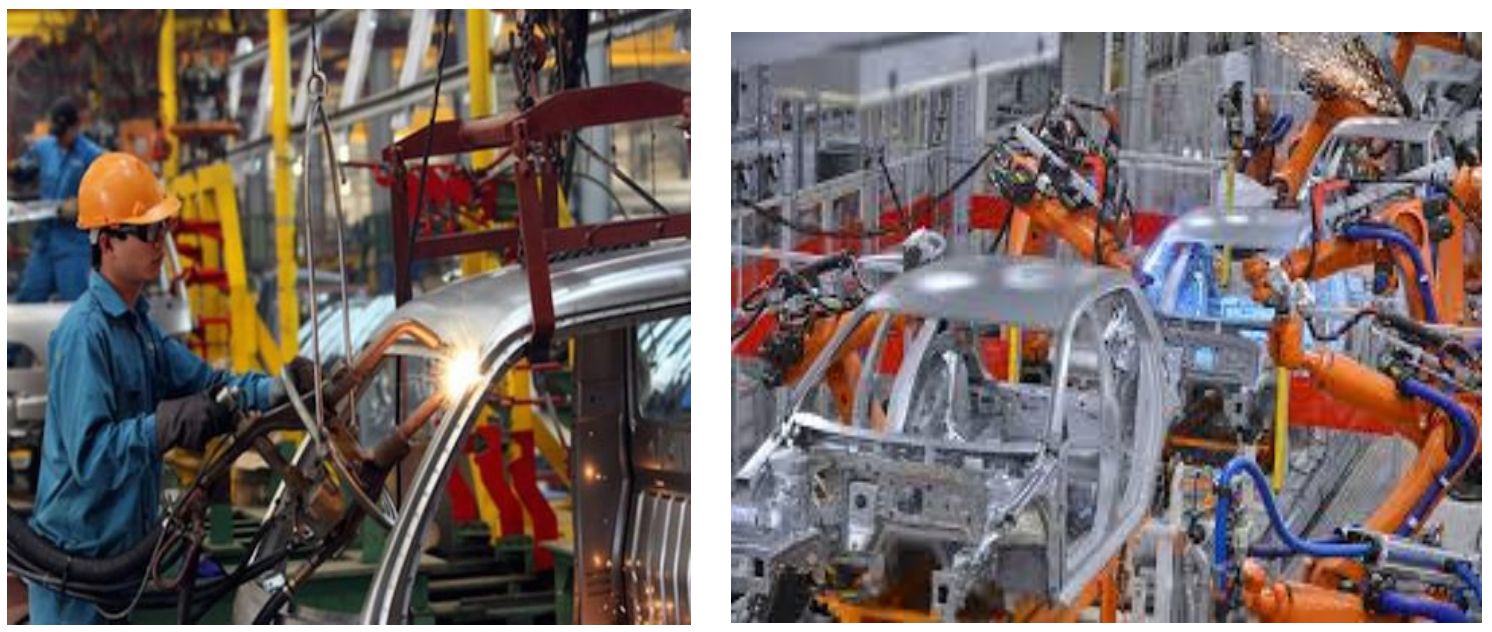

Source: vovworld.vn

Figure 3: A manual spot weld station

BIW welding is carried out either manually or using robots (Figure 2). Most of the modern car manufacturing plants employ a series of robots which carry out the operation. For parts and areas which are difficult to reach through robot arms or for creation of initial templates for use with robots, manual spot welding may be employed (Figure 3). The welding equipment used in both cases comes with adaptive control technology which usually controls the process parameters dynamically based on the variations in the work pieces and the manufacturing environment.

\subsection{Manufacturing Details}

\subsection{Manufacturing process}

In most of the body shop employs Robotic spot welding process for manufacturing of BIW. Robots uses the weld guns to fit the assembly. Each gun is controlled by a weld timer controller unit. Robots are arranged in cells of 1-10 robots in the BIW line but mainly cells of 2-4 robots. There are around 2500-3000 spots made per BIW. Each spot will be associated with a 'spot name' or 'spot code'. The process parameters that will be used for each 
spot name are programmed into the weld-timer controller associated with the gun which is used for that particular spot [2].

Each model of a car will have different sets of spot names. The program related to a particular spot is called in the robot and the weld gun controller based on the automatic identification of the BIW model during the production.

\subsection{Process Parameters}

Process Parameters are those parameters which effect the output of a manufacturing process and determine the quality of a finished product with respect to its specifications. These parameters are usually controlled during a manufacturing process. However, there may be some parameters which may not be controlled during a process due to inherent complexities. Some of the process parameters which determine the output of spot welding are listed below:

- Weld force

- Weld current

- Number of impulses / cycles

- $\quad$ Squeeze time

- Weld time

- Hold time

The resistance of the weld is not a parameter, but a process variable (measured value, not a controlled value)

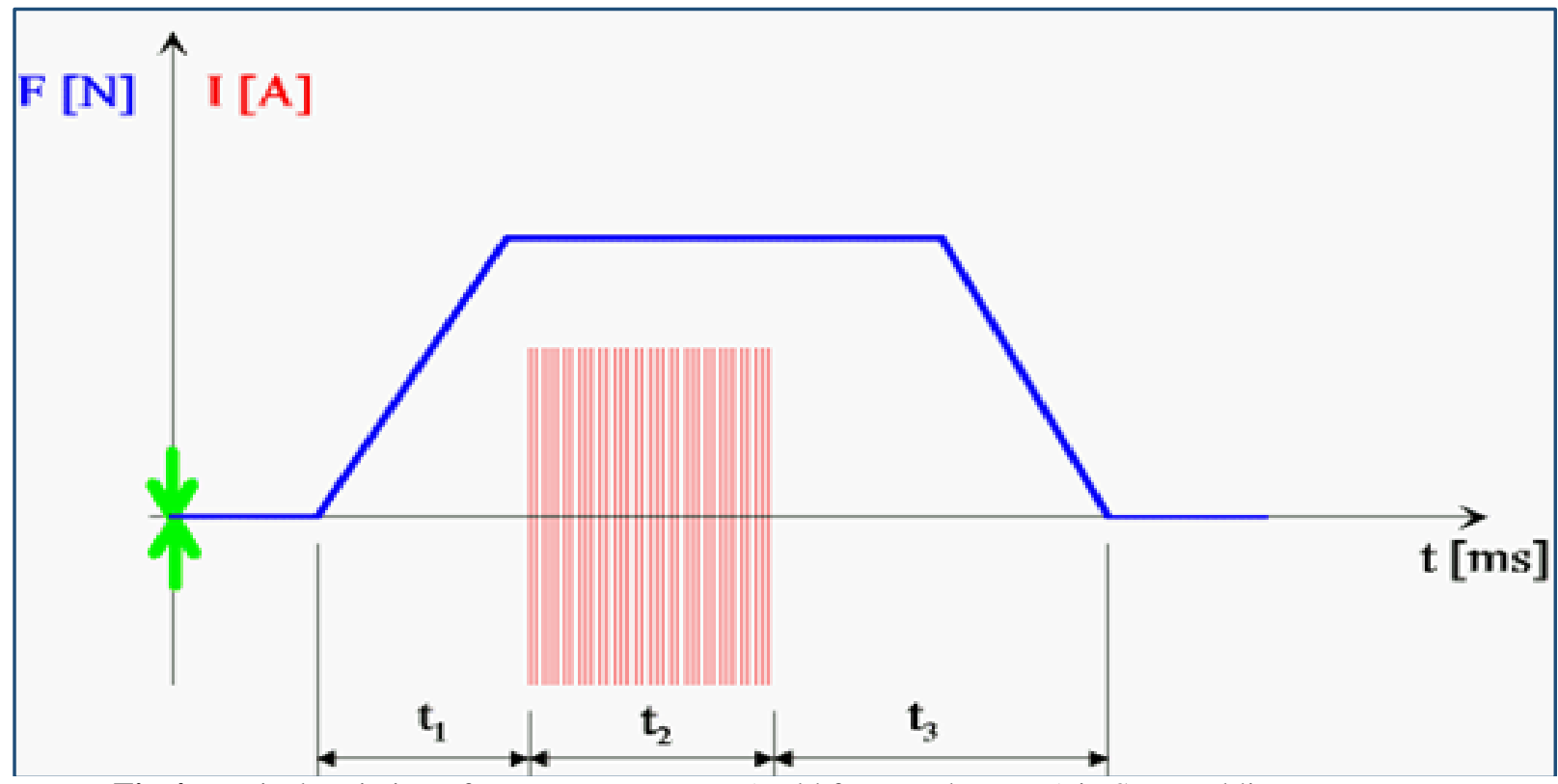

Fig 4: Typical variation of Process parameters (weld force and current) in Spot welding Process

A typical variation of the process parameters like the weld force, Weld current against the time of weld is shown in Figure 4. In the figure, F corresponds to weld force, I corresponds to the weld current, $\mathrm{t} 1$ is the squeeze time, $\mathrm{t} 2$ is the weld time and $\mathrm{t} 3$ is the hold time + release time of the weld.

This spot (AAA) is associated with controller no. 1234 and contains 
1) $50 \mathrm{~ms}$ squeeze time, 2) $60 \mathrm{~ms}$ weld 1 time 3) $30 \mathrm{~ms}$ cooling time 4) $800 \mathrm{~ms}$ weld 2 time 5) 100ms cooling time 6 $100 \mathrm{~ms}$ weld 3 time 7) 600ms hold time 8) $12 \mathrm{kA}$ Weld 1 current 9) $11.5 \mathrm{kA}$ weld 2 current 10) $6 \mathrm{kA}$ weld 3 current 11) Tolerance of $\pm 25 \%$ on weld current

The weld times and the currents are configured based on the energy that is required to create the spot weld. For each spot, these are determined based on empirical data and several trials by the OEM. There are 3 main factors which influence the energy - Current, resistance and time of weld.

$$
\left(\mathrm{E}=\mathrm{I}^{2} \mathrm{R} \mathrm{t}\right)
$$

The controller will be able to control the weld current, time of weld and the resistance by adjusting the welding pressure. However, the resistance varies between one BIW to other because of several reasons like sheet thickness variation, thickness of coating, dust / oil, improper weld tip contact, erosion of electrodes, plate fitting, etc. Due to this, the current passing through the weld and the associated energy also greatly varies. Hence instead of using a fixed parameter for current and time, the controllers use adaptive control technology.

\subsection{Controlling the process parameters}

The adaptive control of the welding system monitors current, voltage and resistance once per millisecond and constantly compares them in real-time against a previously established master resistance curve that controls the quality of the process. The curve is generated through a mathematical calculation of previously captured stored current, voltage and resistance curves of known good welds.

The controllers store the data pertaining to each weld. The following parameters are being monitored and stored for each spot in the welding process in most car manufacturing body shop. Energy - It is the total energy (in Joules) that is spent in creation of the spot for one cycle

a. Resistance - The average resistance (in micro-Ohms) of the weld joint during the cycle

b. Time of weld - Total time (in milliseconds) taken for the weld including the squeeze time and hold time

c. Process stability PSF - A factor calculated by the controller to determine the amount of deviation from the reference resistance curve.

d. Weld Quality Factor UIP - A factor calculated by the controller which gives an indication of the weld quality in general.

e. Wear \%: The electrodes wear out with each weld, i.e. the dimensions of the electrode change because of high heat and pressure. To maintain the dimensional stability the electrodes are periodically dressed. The change in the dimension with each weld and each dressing is shown as a \% of the total life. At $100 \%$ wear the electrode tip is discarded and a new tip is introduced.

f. Actual Voltage: The average voltage during the weld cycle

g. Actual current: The average current during the weld cycle

h. Power: The actual power at which the weld was performed

i. Pulse width: Number of line cycles during which the current is passed. It gives an indication of weld time.

j. $\quad$ uirExpulsionTime: The time during the cycle when a weld splatter has occurred. For example, if the value of uirExpulsionTime is 216 , then it means that a splatter has occurred at $216^{\text {th }}$ millisecond from the start of the cycle

The above parameters are stored in a database of each controller for each spot of each BIW against the timestamp when the spot is made. There is a huge amount of data that is generated per day.

\subsection{Inspection Process (Detection of Defects)}

\subsection{Ultrasound probe measurement}

The quality of the spot weld is currently checked (detected) using Ultrasound probe measurement. Around 2 cars per day are selected manually from the production lot and manual measurement of the spot welds is carried out using ultrasound probes. Once the user logs on to the ultrasound measurement system, the system presents an inspection plan. The plan specifies the spot numbers to be measured. The user then follows the plan and places the probe over the spot which is prompted by the system. The system then records the Total thickness of the welded plate and stores in the database. Once the total thickness is measured, the measurement system also indicates the following characteristics of the weld nugget: 
- Small weld (lesser nugget diameter than the specified diameter) - A value of 1 indicates that the nugget diameter is less than the specified limit

- $\quad$ Stick weld ( 1 or 0$)$ - A value of 1 indicates that the weld is not proper and it is a stick weld

- $\quad$ Bad through weld (1 or 0$)$ - A value of 1 indicates that the plates have been pierced instead of being joined.

Due to the huge volumes involved and the cycle time constraints in carrying out the inspection. All BIWs and all spots in a BIW cannot be measured using the Ultrasound probe.

\subsection{Destructive Testing}

There is also destructive testing done (tear down testing). One car / month is tested this way. The welded plates get pulled apart and the plates should shear at the spot-welds. The resulting nugget gets measured and logged for every spot. The results are stored manually in offline files.

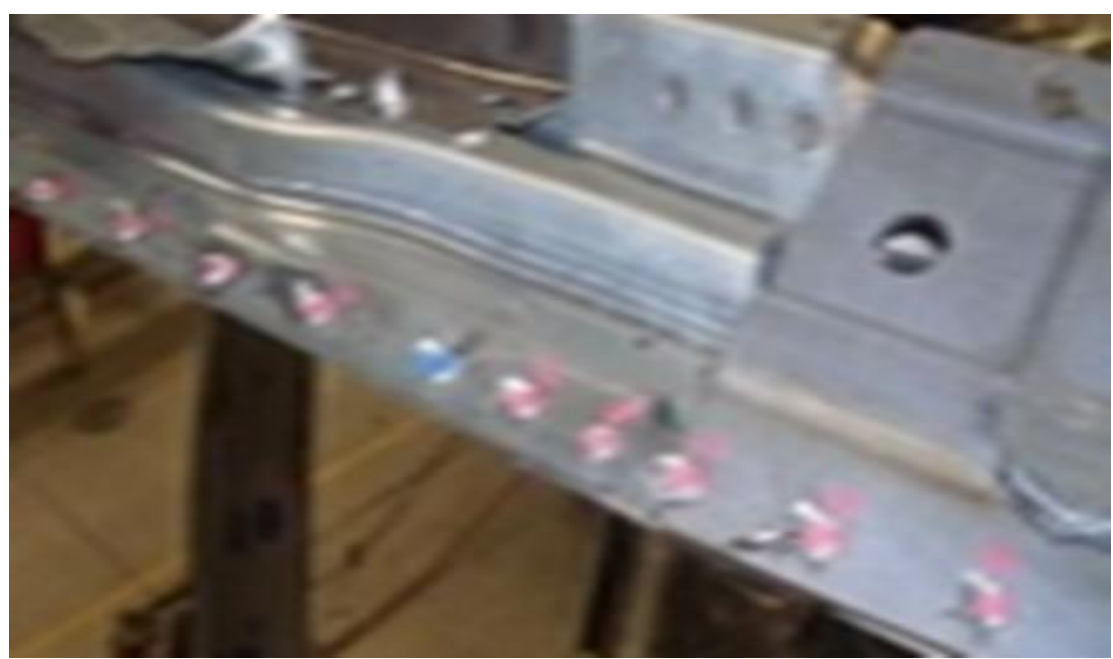

Figure 5: Teardown Test

\section{An Intelligent Model for Defect Prediction in spot welding methodology}

There are three major defect that affect the quality of weld

\begin{tabular}{|c|l|}
\hline S.No & Defects \\
\hline 1 & Small nugget \\
\hline 2 & Stick weld \\
\hline 3 & Bad through Weld \\
\hline
\end{tabular}

Table 1: Defects 
The following are the process parameters majorly contribute to the defect occurrence if there an change in characteristics

\begin{tabular}{|l|l|}
\hline S.No & Process Parameter \\
\hline 1 & Weld Current \\
\hline 2 & Resistance \\
\hline 3 & Weld time \\
\hline 4 & Pulse width \\
\hline 5 & \begin{tabular}{l} 
Power \\
\hline 6
\end{tabular} \\
\hline 7 & \begin{tabular}{l} 
Electrode wear \% \\
Stabilisation factor \\
\hline 8
\end{tabular} \\
\hline Process Quality factor \\
\hline
\end{tabular}

Table 2: Process Parameters

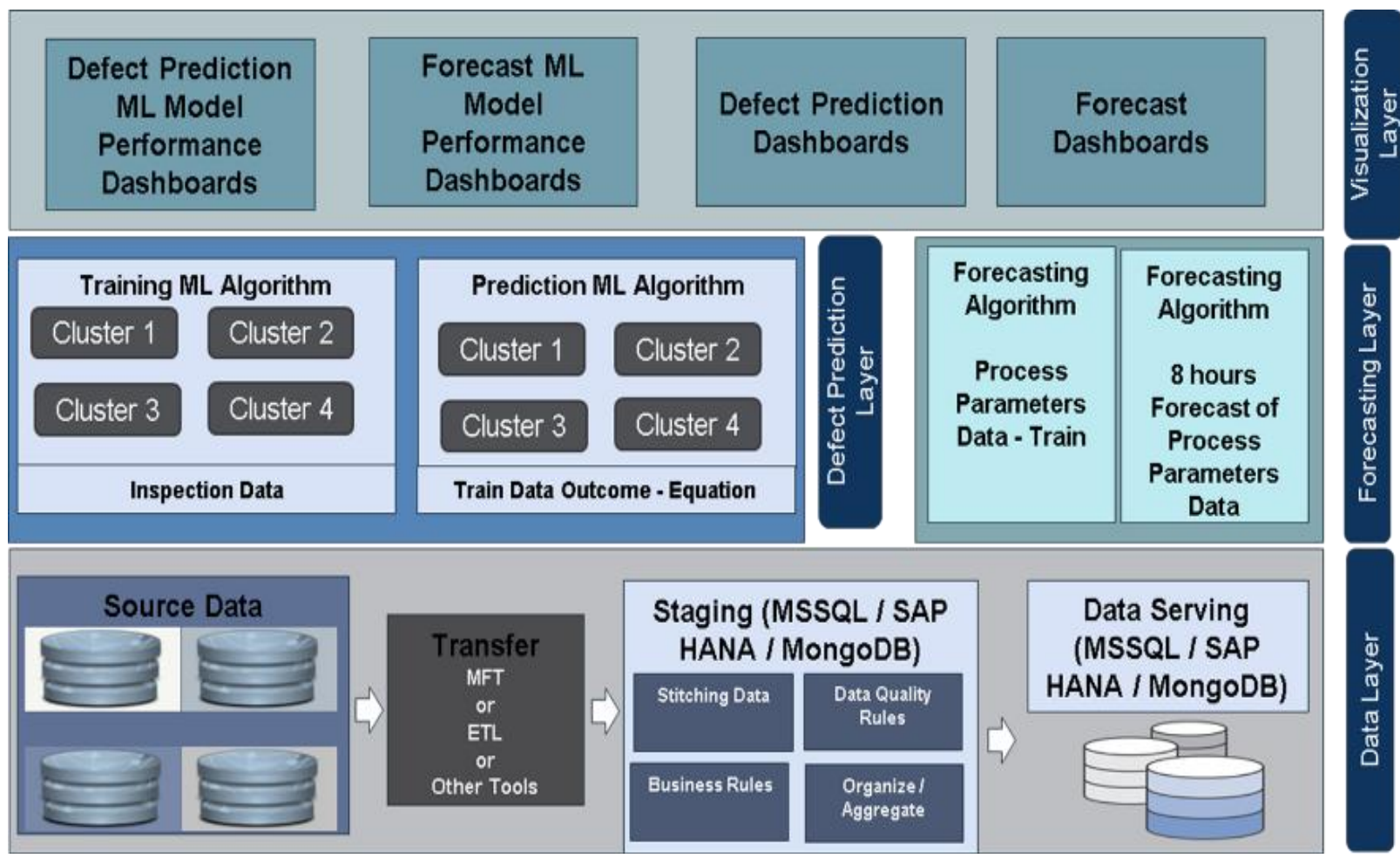

Figure 6: Methodology

An intelligent Model for Defect Prediction in Spot Welding methodology has the following components or process for intelligent defect prediction.

\subsection{Data Layer}

The source data is gathered in staging DB and the following action taken on data 1) Stitching 2) Data Quality Rules 3) Business Rules and 4) Aggregate and Organize. Now the data is ready serve.

\subsection{Defect Prediction Layer}

Each cluster is having one model for prediction of defects. Each spot uses different cluster based on their confusion matrix results.

The below approach is followed for model or algorithms selection for spots. The following algorithms used to build the models for the prediction of defects.

\subsection{Machine Learning Algorithms}


* K Nearest Neighbor

* Naves Bayes

* Decision Tree

* Support Vector Machines

\subsection{Forecasting Layer}

.The below approach is followed for model or algorithms selection for spots. The following algorithms used to identify behaviour and characteristics. Up normal behaviour of process parameter notified to operators to stop the machine.

\subsection{Time Series Algorithms}

For the forecasting the following algorithms used

$>$ ANN

$>$ ARIMA

$>\mathrm{ES}$

\section{APPROACH FOLLOWED FOR ALGORITHM SELECTION}

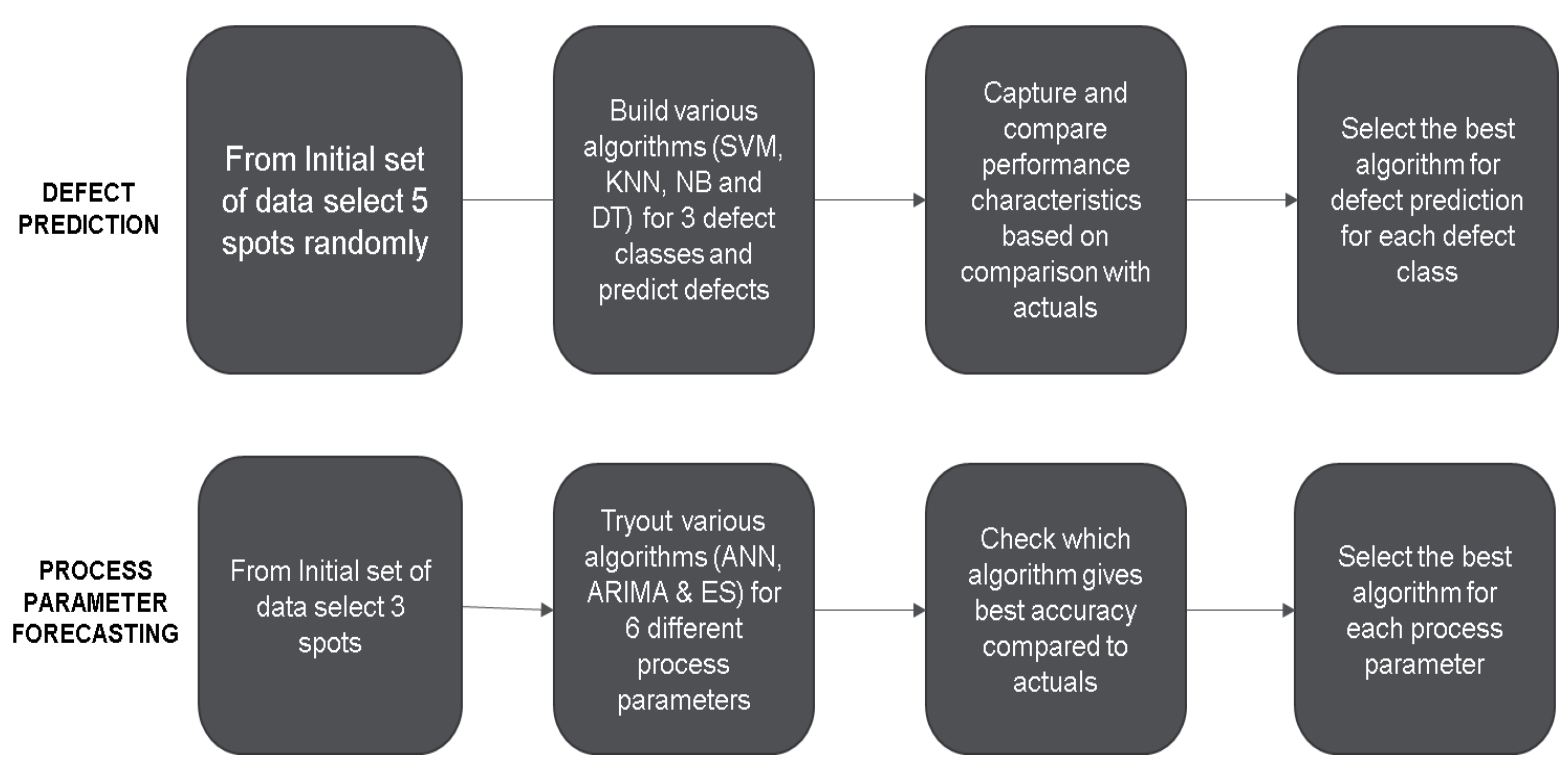

Figure 7: Approach Followed for Selection of Algorithms

\subsection{Visualization Layer}


In this layer prediction, forecasting and model performance dashboard and reports displayed various dimension. This helps the operator infer and to take decision immediately. This also help the testing team to select the spot welding based on prediction and process parameters behavior. .



Figure 8: Defect Prediction - Spot

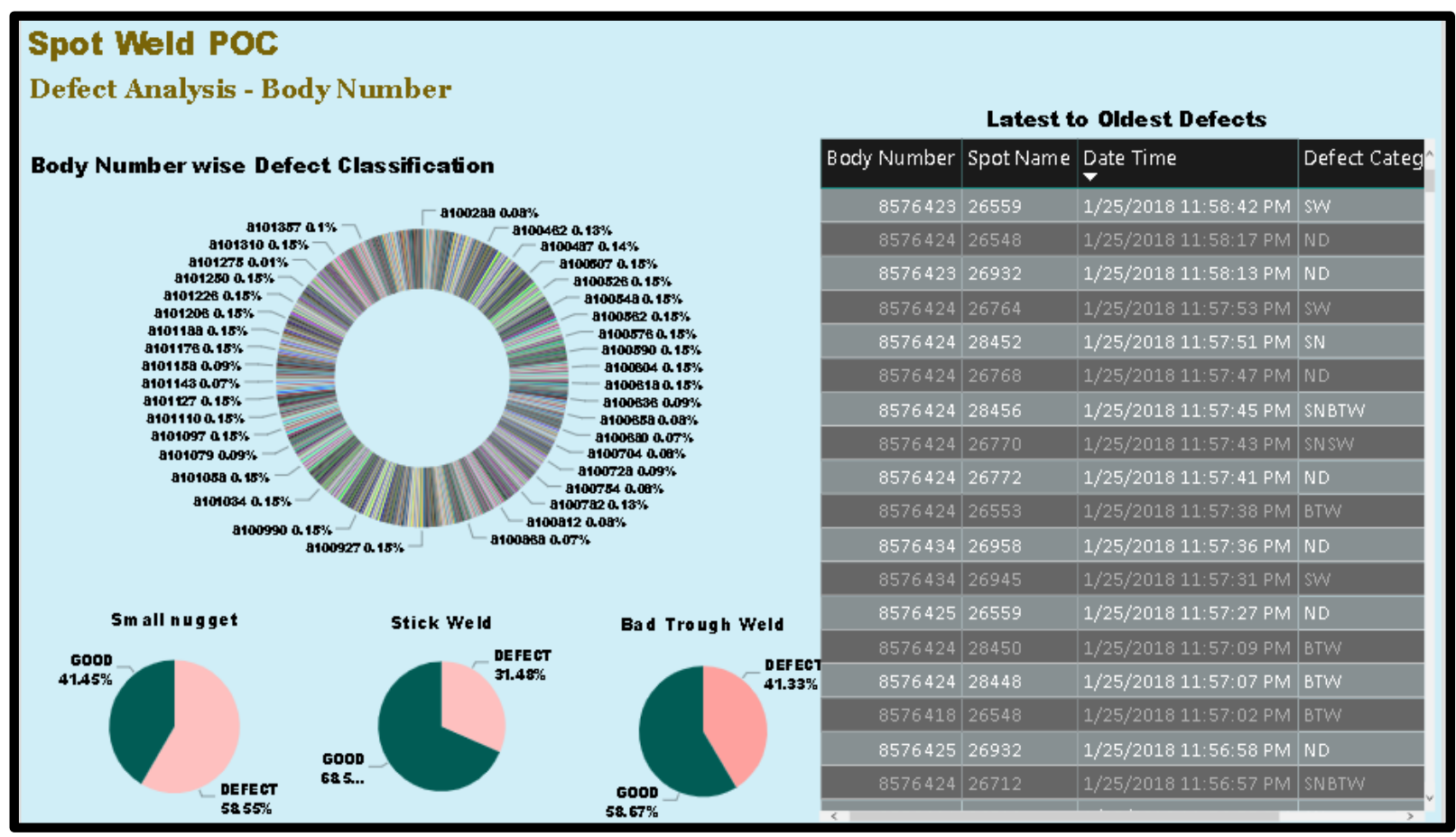

Figure 9: Defect Prediction - Body 


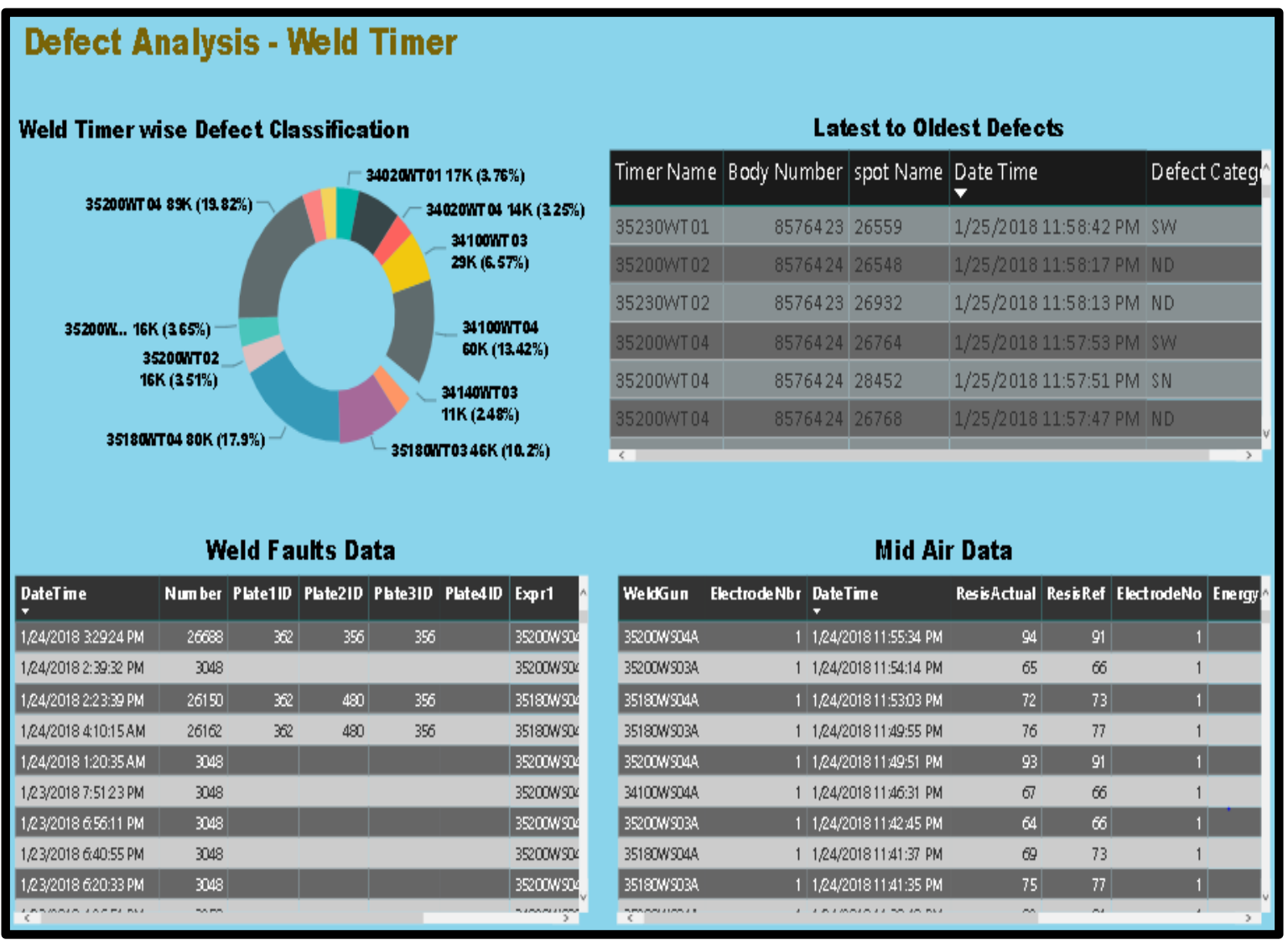

Figure 10: Defect Prediction - Weld Timer

\section{Computational Efficiency}

The accuracy of the methodology output $70 \%$ and it is better than $50 \%$ \& below from existing methodology. This methodology uses the clustered environment to give the output in real time. It predicts real time defects, and this will help to stop spot welding and identify root cause if more defects are predicted. This will help to fix the problem immediately. The $70 \%$ will improve further as the machine learning execution happens.

\section{Experimental Result}

The existing method is unpredictable, and it is more error prone. The accuracy of welding is around 50\% as sample data.

As per the confusion matrix the Accuracy is average $70 \%$, Specificity $60 \%$ and Sensitivity $75 \%$ for all three defects. 




Figure 11: Confusion Matrix and Forecast Accuracy

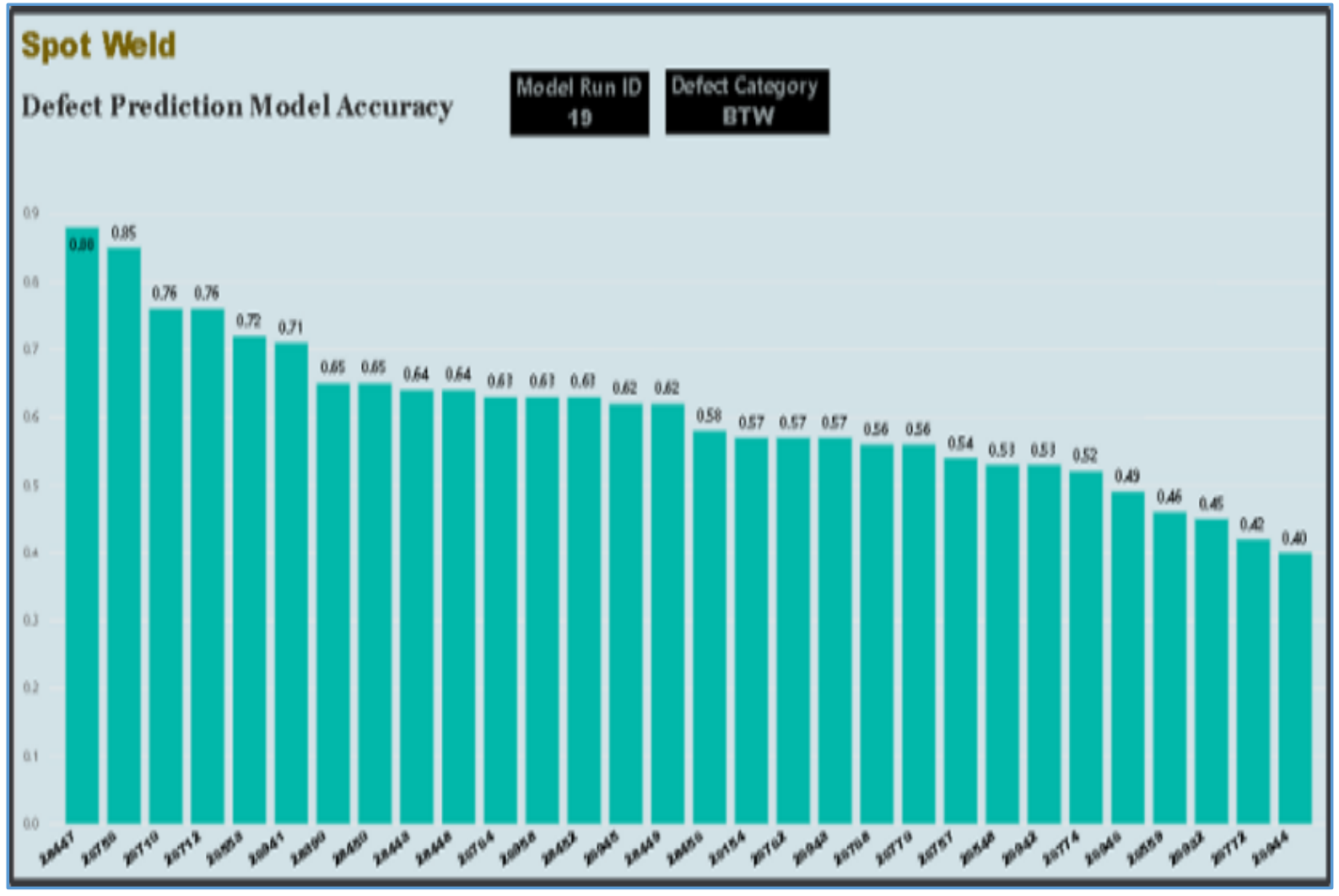

Figure 12: Spots Accuracy

As per the experiment data the existing methodology for spot welding stands at 1.78 Six Sigma and for the defect prediction optimized methodology (after) stands at 4.76 Six Sigma. This shows huge improvement in methodology. Please see the figure below. 


\section{Report 1: Executive Summary}
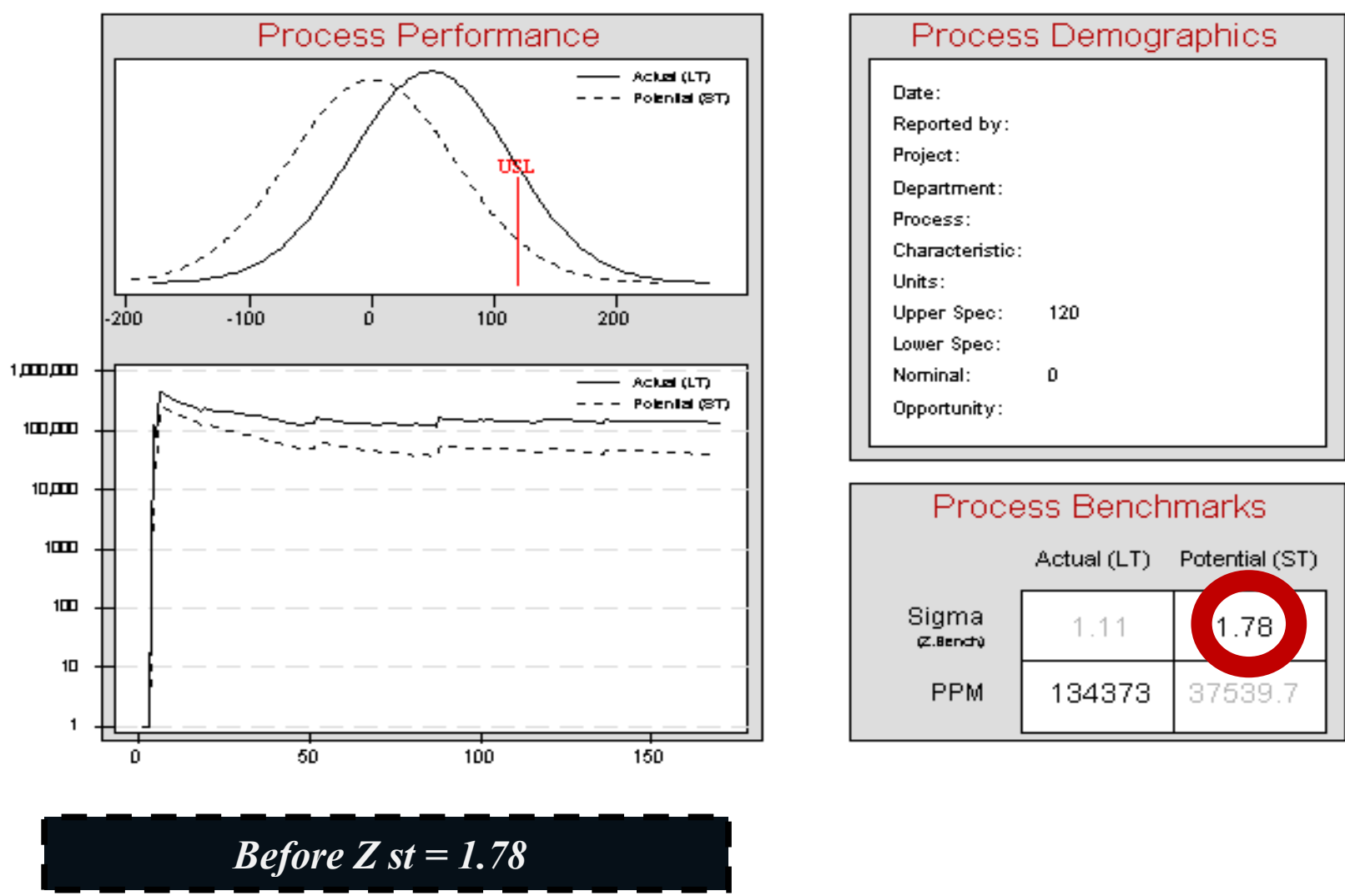

Report 1: Executive Summary



Figure 13: Six Sigma value before and after improvement

\section{Conclusion and Future Scope}

An Intelligent Model for Defect Prediction in spot welding methodology is helping to control and reduce spot weld defects, unnoticed defect in production and optimized testing. Also this helps in planning and decision making for future spot welding. 
Future research should be carried out to stop the machine immediately if defect occurs.

\section{References}

Zoha Nasir, Dr.M.I.Khan “ Resistance spot welding and optimization techniques used to optimize its process parameters” International Research Journal of Engineering and Technology (IRJET)” - Volume: 03 Issue: 05 | May-2016 - 886 -893 - 2016.

Kamal Shelly1, D.S.Sahota2 “A Review Paper on Resistance Spot Welding of Austenitic Stainless Steel 316” International Journal of Engineering Trends and Technology (IJETT) - Volume 47 Number 7 May 2017 424-428- 2017

Thongchai Arunchai,1 Kawin Sonthipermpoon,1 Phisut Apichayakul,1 and Kreangsak Tamee2 "Resistance Spot Welding Optimization Based on Artificial Neural Network" - International Journal of Manufacturing Engineering - Volume 2014, Article ID 154784, 6 pages - http://dx.doi.org/10.1155/2014/154784 - 1-6 2014.

Gerhard Posch, Jürgen Bruckner, Helmut Ennsbrunner "Industry 4.0 Welding" - 4-8- 2018

Robert Sierlinger, Martin Gruber and voestalpine Stahl GmbH "A CRACKING GOOD STORY ABOUT LIQUID METAL EMBRITTLEMENT DURING SPOT WELDING OFADVANCED HIGH STRENGTH STEELS" - 6-10 - 2017

Ethem Alpaydın "Introduction to Machine Learning" 50-250-Jan-2015

PETER HARRINGTON “ Machine Learning in Action” - 100-300 - 2012

SHAI SHALEV-SHWARTZ and SHAI BEN-DAVID "Understanding Machine Learning: From Theory to Algorithms" 200-300- May- 2014

Brett Powell "Mastering Microsoft Power BI" - 300-500-Jan-2018

PETER HARRINGTON "Machine Learning in Action" - 100-200-April-2012

SHAI SHALEV-SHWARTZ and SHAI BEN-DAVID "Understanding Machine Learning: From Theory to Algorithms" - 200-400-May-2014

Ian F. Darwin "Java Cook Book" -400-600-April-2014

Thomas W. Miller Modeling Techniques in Predictive Analytics with Python and R - A Guide to Data Science" 300-500-September-2018

Albright and Winston "Business Analytics, Data Analysis and Decision Making” - 400-600-Jan-2015

Foster Provost and Tom Fawcett "Data Science for Business" -200-400-July-2013 